(2) Open Access Full Text Article

REVIEW

\title{
Removal of excess skin after massive weight loss: challenges and solutions
}

This article was published in the following Dove Press journal:

Open Access Surgery

8 June 2015

Number of times this article has been viewed

\section{Salvatore Giordano}

Department of Plastic and General Surgery, Turku University Hospital, Turku, Finland
Correspondence: Salvatore Giordano Department of Plastic and General Surgery, Turku University Hospital, OS 299, PL 52, 2052I, Turku, Finland $\mathrm{Tel}+35823130521$

Fax +35823132284

Email salvatore.giordano@gmail.com
Abstract: The advent of bariatric surgery has led to a subspecialty in plastic surgery for skin and fat contouring which remain after massive weight loss. The author discusses the preoperative assessment, surgical treatment plan, postoperative management, possible complications, and benefits of postbariatric surgery. Preoperative planning includes medical history and patient assessment. Surgical procedures for brachioplasty, upper back lift, breast reshaping, abdominoplasty, panniculectomy, lower back lift, and thigh lift are discussed. Indications, postoperative complications, and benefits are also discussed. The best candidates for postbariatric plastic surgery are those who have achieved weight loss stability with a BMI of 32 or less and who have adequate nutrition in order to heal the surgical excisions. Abdominal and truncal deformity are the most common presenting complaints in massive weight loss patients, and the procedure of choice to address this region is a body lift. Postoperative care focuses on patient safety, prioritizing in deep venous thrombosis (DVT) prophylaxis and seroma prevention. Postbariatric body contouring aims to correct the deformity due to the excess of skin after massive weight loss and to restore a sense of normalcy.

Keywords: morbid obesity, bariatric surgery, weight loss, massive weight loss, body contouring, panniculectomy

\section{Introduction}

Obesity is when body weight exceeds ideal body weight (IBW) by $20 \%$ or a body mass index (BMI) of 30-35 kg/m². In 1991, the National Institutes of Health defined morbid obesity as a BMI of greater than $35 \mathrm{~kg} / \mathrm{m}^{2}$ with severe obesity-related comorbidity or a BMI of greater than $40 \mathrm{~kg} / \mathrm{m}^{2}$ without comorbidity (Table 1). ${ }^{1}$ Obesity is further classified into different types according to BMI (Table 2). ${ }^{2}$

In Finland, $70 \%$ of men and $56 \%$ of women are overweight (BMI, 25-30), with an overall obesity prevalence (BMI $>30$ ) of $23 \%$ among adults. ${ }^{3}$ Based on the latest estimates in European Union countries, over $50 \%$ of the people are overweight or obese. ${ }^{4}$ More than one-third (34.9\% or 78.6 million) of US adults are obese. ${ }^{5}$

Obesity increases the risk of complications and mortality in many surgical procedures because of its correlation with deficient wound healing. ${ }^{6}$

In obesity there is an excess of body fat, which can be distributed equally all over the body or concentrated in particular regions. There are sex differences in the distribution of body fat. Males have less body fat, which is usually distributed around the waist, especially in the abdominal area, and this type of fat distribution is called android. Females normally have a higher fat percentage than men and fat is deposited around 
Table I National Institutes of Health (NIH) classification by body mass index (BMI)

\begin{tabular}{ll}
\hline BMI $\left(\mathbf{k g} / \mathbf{m}^{2}\right)$ & Class \\
\hline $25-29.9$ & Overweight \\
$30-34.9$ & Class I (low risk) obesity \\
$35-39.9$ & Class II (medium risk) obesity \\
$\geq 40$ & Class III (high risk) obesity \\
\hline
\end{tabular}

their thighs and buttocks; this type of distribution is called gynecoid. Therefore, obese women tend to deposit fat in the lower part of the body.

To date, bariatric surgery is the most effective treatment for morbid obesity. ${ }^{7}$ The efficacy of bariatric procedures in the induction and maintenance of weight loss is largely superior to that obtainable by current medical therapies. ${ }^{7,8}$ Surgery results in greater improvement in weight-loss outcomes and weight-associated comorbidities compared with nonsurgical interventions, regardless of the type of procedure used. ${ }^{9}$

Massive weight loss (MWL) following bariatric surgery has created a fast-growing population of patients eligible for body contouring with a unique combination of problems and an increasing demand for these procedures. ${ }^{10}$ Indeed, clear guidelines for treating these patients are still lacking.

\section{Body contouring after massive weight loss}

MWL is defined as the loss of greater than $100 \%$ above the person's IBW..$^{11,12}$ Although this amount of weight loss is most commonly found in bariatric surgery settings, plastic surgeons should distinguish between patients who have undergone bariatric/metabolic surgery and those who have lost weight only through diet and exercise, because malabsorptive procedures produce a number of nutritional deficiencies not otherwise seen. Furthermore, they need to understand the differences between different bariatric surgical techniques and take their basic working mechanism into consideration as patients having purely restrictive procedures are less likely to suffer from many of the metabolic complications and deficiencies that may be seen after malabsorptive weight loss operations. ${ }^{13}$

Table 2 Classification of morbid obesity

\begin{tabular}{ll}
\hline Type of obesity & BMI $\left(\mathbf{k g} / \mathbf{m}^{2}\right)$ \\
\hline Obesity & BMI $>30$ \\
Severe obesity & BMI $>35$ \\
Morbid obesity & BMI $>40$ \\
Superobesity & BMI $>50$ \\
Supersuperobesity & BMI $>60$ \\
\hline
\end{tabular}

Abbreviation: BMI, body mass index.
The terms, body contouring or post-MWL body contouring, can be applied to any surgical procedure used to modify the skin envelope, subcutaneous layer, and/or investing fascia, and includes a wide range of operations performed to treat the MWL patient.

After a rapid and massive weight loss, there is a sudden change in BMI which leads to skin and soft tissue becoming redundant with a poor tone. Surplus skin and malpositioned adipose deposits can contribute to medical conditions such as irritation, fungal infections, poor hygiene, skin breakdown, physical function impairments, and low self-esteem. ${ }^{13}$ Therefore, excisional surgery may relieve these symptoms and, for all these reasons, it should be considered to be reconstructive rather than cosmetic. ${ }^{14}$ However, MWL patients are also seeking an aesthetic outcome to improve their body image and self-esteem.

\section{Medical comorbidities and nutritional assessment}

Many morbidly obese patients have significantly improved their medical status because of bariatric surgery. ${ }^{9}$ However, any medical problems and psychosocial issues should be assessed and addressed before surgery with an appropriate multidisciplinary consultation in order to optimize the patient for the procedure. ${ }^{15}$

A history of dumping syndrome and its duration need to be assessed, as well as constitutional symptoms, like nausea and vomiting, because a prolonged emesis can be the sign of a mechanical problem requiring further investigations on the part of the bariatric surgeon. ${ }^{13}$ Although vast medical improvement is seen with significant weight loss, the plastic surgeon must critically evaluate unsolved medical issues (diabetes, cardiac disease, obstructive sleep apnea, and venous thromboembolism risk). ${ }^{13}$

Particular attention must be paid to the patient's current prescription medication regimen. Antiplatelet and nonsteroidal anti-inflammatory agents must be discontinued for at least 2 weeks before surgery. Specifically, the surgeon must ask about any herbal medications or nutritional supplements used by the patients. ${ }^{16}$

The negative effects of tobacco smoke should be pointed out, and surgery should be deferred for all active smokers. One month before surgery, a urine cotinine test can be administrated to prove that the patient is tobaccofree. ${ }^{17,18}$

Preoperative appropriate nutritional assessment remains crucial. Malabsorptive deficiencies may be less common in patients previously treated by restrictive procedures. 
However, they might present with nutritional derangements secondary to caloric restriction. ${ }^{13}$

Medications and nutritional supplements, such as iron, Vitamin $B_{12}$, calcium, and multivitamins, are often prescribed after laparoscopic Roux-en-Y gastric bypass (LRYGB). It is important to assess the amount of daily protein intake and the perioperative goal of 70-100 g/day is encouraged. ${ }^{19}$ Therefore, the preoperative laboratory work-up should include metabolic and nutritional parameters, like hematocrit, hemoglobin, basic metabolic panel, and prealbumin levels, as inadequate nutrition is common among postbariatric patients presenting for body contouring. ${ }^{20}$

Finally, particular attention should be paid to previous incisions that may compromise blood flow to flaps elevated during body-contouring procedures. Hernias are common in patients who have undergone open surgical procedures (laparotomy, cholecystectomy) while still obese, and there might be a need for abdominal wall reconstruction affecting the surgical plan. Indeed, superficial venous varicosities should be considered in the patient undergoing contouring of the thigh. ${ }^{13}$

\section{Patient selection}

Most postbariatric patients desire body contouring, and a number of studies have shown that from $25 \%$ up to $54 \%$, and as many as $84.5 \%$ of postbariatric patients desire body contouring, but only $21 \%-25 \%$ actually undergo these procedures. . $^{10,12,15,21-24}$

Assessing candidates' weight fluctuations over time is important in order to understand whether the patient has recently gained or lost weight, or if the patient has reached a plateau. A stable weight reduces the rate of complications and leads to better cosmetic results. ${ }^{25}$ In terms of timing, surgery should be performed when the patient's weight is stable, with recommendations of 12-18 months following the bariatric operation and 4-6 months without weight fluctuation. Usually, the lower the BMI at the time of body contouring, the better the cosmetic result and the lower the rate of surgical complications. ${ }^{24}$ Therefore, patients still willing to lose weight should postpone the surgery for a period of 6 months until they reach their optimal weight; otherwise, sagging skin will occur again.

To date, there is no clear BMI cut-off above which surgery should be refused, but some authors recommended that the upper limit for MWL surgery should not exceed a current BMI of 32, because higher BMIs have been associated with increased risk of complications. ${ }^{26}$ However, MWL patients may have an artificially elevated BMI from rolls of redundant skin. ${ }^{27}$
An attempt to define national guidelines has recently been proposed in the $\mathrm{UK},{ }^{28}$ requiring a $\mathrm{BMI}<28$ and/or an excess weight loss percent $>75 \%$ with a weight stability of over 12 months. Similarly, in Finland, guidelines have been proposed in 2010 with a BMI cut-off of 32, but panniculectomy can be performed for improving patients' functions. ${ }^{29}$ In Sweden, abdominoplasty in postbariatric surgery patients is indicated if the panniculus hangs over $3 \mathrm{~cm}$ within a stable BMI $<30$, (while in Denmark BMI has to be $<30$ and a $\Delta \mathrm{BMI}>15){ }^{30}$

Plastic surgeons should be very selective when dealing with patients presenting with a BMI between 30 and 35 , looking at individual patterns of body fat distribution to guide surgical planning. For example, a patient with an android body type might have a large intra-abdominal fat amount that limits an effective abdominal contouring. Similarly, patients with a BMI between 35 and 40 tend to have a thicker subcutaneous adipose layer, also limiting aesthetic contouring, although they might be good candidates for liposuction. Thus, for these patients, functional procedures like panniculectomy or reduction mammaplasty can improve comfort during exercise and facilitate further weight loss. ${ }^{13,15}$

A complete evaluation of anatomic deformities is needed for planning the specific procedures. Skin redundancy and quality, lipodystrophy, and adherent folds have to be noted. Furthermore, varicose veins, lymphedema, and overall scar evaluation are also important. ${ }^{13}$

The Pittsburgh rating can facilitate the preoperative planning and is a useful tool in quantifying the improvement after surgery with systematic assessing and quantifying of the deformities for each body region (Table 3 ). ${ }^{31}$

Patient expectations must be assessed at the initial patient consultation. Generally, postbariatric surgery patients want the procedure immediately, they want perfect results, no downtime, and no risks. ${ }^{15} \mathrm{~A}$ recent study showed that $36.4 \%$ of postbariatric surgery patients have very high expectations as to how body contouring might change their appearance. ${ }^{27}$ Thus, patients have to be informed that body-contouring procedures are complex and labor-intensive, with big scars, long recovery times, and common wound healing complications. ${ }^{12}$ Patients presenting for postbariatric reconstruction should be aware that the procedures are mostly functional and the results may not be equivalent to an aesthetic surgery operation. ${ }^{23}$

Overall, the MWL patient population is satisfied after body-contouring surgery with an improved quality of life, ${ }^{32-38}$ also in the long-term. ${ }^{25}$ However, preoperative photographs are kept in the patient record in order to show the dramatic differences in overall contour in case of issues about minor 
Table 3 Pittsburgh weight loss deformity scale

\begin{tabular}{|c|c|c|}
\hline Area & Scale & Definition \\
\hline \multirow[t]{4}{*}{ Arms } & 0 & Normal \\
\hline & I & Adiposity with good skin tone \\
\hline & 2 & Loose, hanging skin without severe adiposity \\
\hline & 3 & Loose, hanging skin with severe adiposity \\
\hline \multirow[t]{4}{*}{ Breasts } & 0 & Normal \\
\hline & I & Ptosis grade I or 2 or severe macromastia \\
\hline & 2 & $\begin{array}{l}\text { Ptosis grade } 3 \text {, or moderate volume loss, or } \\
\text { constricted }\end{array}$ \\
\hline & 3 & $\begin{array}{l}\text { Severe lateral roll and/or severe volume loss } \\
\text { with laxity }\end{array}$ \\
\hline \multirow[t]{4}{*}{ Back } & 0 & Normal \\
\hline & I & Single fat roll or adiposity \\
\hline & 2 & Multiple skin and fat rolls \\
\hline & 3 & Ptosis of rolls \\
\hline \multirow[t]{4}{*}{ Abdomen } & 0 & Normal \\
\hline & 1 & $\begin{array}{l}\text { Redundant skin with rhytides or moderate } \\
\text { adiposity without overhang }\end{array}$ \\
\hline & 2 & Overhanging pannus \\
\hline & 3 & Multiple rolls or epigastric fullness \\
\hline \multirow[t]{4}{*}{ Flank } & 0 & Normal \\
\hline & I & Adiposity \\
\hline & 2 & Rolls without ptosis \\
\hline & 3 & Rolls with ptosis \\
\hline \multirow[t]{4}{*}{ Buttocks } & 0 & Normal \\
\hline & I & $\begin{array}{l}\text { Mild to moderate adiposity and/or mild to } \\
\text { moderate cellulite }\end{array}$ \\
\hline & 2 & Severe adiposity and/or severe cellulite \\
\hline & 3 & Skin folds \\
\hline \multirow[t]{4}{*}{ Mons } & 0 & Normal \\
\hline & I & Excessive adiposity \\
\hline & 2 & Ptosis \\
\hline & 3 & Significant overhanging below symphysis \\
\hline Hips/lateral & 0 & Normal \\
\hline \multirow[t]{3}{*}{ thigh } & I & $\begin{array}{l}\text { Mild to moderate adiposity and/or mild to } \\
\text { moderate cellulite }\end{array}$ \\
\hline & 2 & Severe adiposity and/or severe cellulite \\
\hline & 3 & Skin folds \\
\hline \multirow[t]{4}{*}{ Medial thigh } & 0 & Normal \\
\hline & 1 & Excessive adiposity \\
\hline & 2 & Severe adiposity and/or severe cellulite \\
\hline & 3 & Skin folds \\
\hline Knees/lower & 0 & Normal \\
\hline \multirow[t]{3}{*}{ thigh } & I & Adiposity \\
\hline & 2 & Severe adiposity \\
\hline & 3 & Skin folds \\
\hline
\end{tabular}

wound-healing problems, scar asymmetry, spitting sutures, seromas, and other minor complications. ${ }^{38}$

Body dysmorphic disorder might be present in this population and it is recommended to identify this before surgery. Thus any patient with a psychiatric diagnosis beyond simple depression should be followed up. ${ }^{37}$

Staging procedures can be beneficial in order to limit the surgical time, because longer operating times are associated with an increased rate of complications. ${ }^{12}$ Therefore, multiple procedures can be combined safely, resulting in less anesthetic time, less blood loss, and reduced surgeon fatigue. ${ }^{38}$ Great effort should be applied to understand which anatomic areas are of greatest concern to the patient. A typical approach to staging for a MWL patient desiring total body contouring includes, firstly, lower body lift including breast or arm procedures, followed by medial thigh, and upper back surgery. Facial rejuvenation procedures are performed last. ${ }^{38}$

The patient's highest priority body areas should be addressed and treated first, and a period of at least 3 months between stages is recommended because of wound healing and scar stabilization. ${ }^{11,15}$

\section{Body-contouring procedures}

Body-contouring procedures following MWL can be divided into lower body lift or belt lipectomy, thigh lift, brachioplasty, upper body lift, and breast reshaping. Venous thromboembolism prophylaxis includes the use of compression device, flexing the knees on a pillow, and, more important, postoperative administration of low-molecular-weight heparin or unfractionated heparin. ${ }^{11,39}$ Intraoperative fluid management should be monitored continuously by blood pressure, urinary output, and estimated blood loss. ${ }^{12,40}$ Indeed, postbariatric patients have an elevated risk for hypothermia, so it is important to maintain a normothermic temperature and reduce the time of exposure. Finally, operative time should preferably be kept under 6 hours to minimize complications. ${ }^{38,41}$

Although many surgical operations can be performed safely without prophylactic drainage, drain placement following postbariatric surgery procedures is recommended to prevent or reduce seroma formation. ${ }^{11,42}$ The timing of drain removal is the surgeon's choice as there is no evidence at present about this issue. ${ }^{42}$

The overall risk for venous thromboembolism is about $2.9 \%$ for all patients undergoing body-contouring surgery. This rate can increase to $8.9 \%$ for patients with a BMI $>35 .{ }^{11}$ All patients should be treated with intermittent pneumatic compression devices applied before the induction of general anesthesia, and consideration should be given to the use of unfractionated or low-molecular-weight heparin on the night of the surgery or during the postoperative period, on the basis of established risk factors. ${ }^{43}$

Edema is particularly common after surgery on the arms or legs, especially after extended thigh lifts. Compressive wrapping from distal to proximal and elevation may be performed by the patient. Good nutrition is crucial after large excisional lifting procedures. Protein and vitamin intake should be optimized, as well as patient hydration. ${ }^{12}$ 
Postbariatric surgery procedures are mostly clean surgeries, therefore, antibiotic prophylaxis is only indicated when the operation lasts more than 3 hours and/or the American Society of Anesthesiologists score is 3 or more. ${ }^{44}$

Postoperative pain management should be carried out through the use of multimodal analgesia, but other modalities such as regional blocks, pain pumps, and patient positioning should also be considered. ${ }^{45,46}$

\section{Brachioplasty}

Traditional brachioplasty includes incisions along the length of the upper arm, worked out within the axilla, and, for batwing deformity, it can continue along the lateral chest wall. ${ }^{47}$ Markings are drawn with the arm elevated at $90^{\circ}$; they are guided by pinch test along the arm and may require intraoperative modification. Recent reports showed that additional liposuction is a safe and efficient technique ${ }^{48}$ but we prefer to limit it, because it may exacerbate skin laxity. Incision is often posterior to the antebrachial groove, deepening to the fascia overlying muscle and neurovascular structures, taking care to avoid injuries to the medial antebrachial cutaneous nerve, near the basilic vein in the distal third of the arm (Figure 1). ${ }^{49}$

\section{Upper back lift}

Upper back lift is indicated in patients with a pronounced upper back skin laxity. It is best performed at a different time from lower body lift because of opposing lines of tension. ${ }^{50}$ Markings are made, with the patient standing, across the
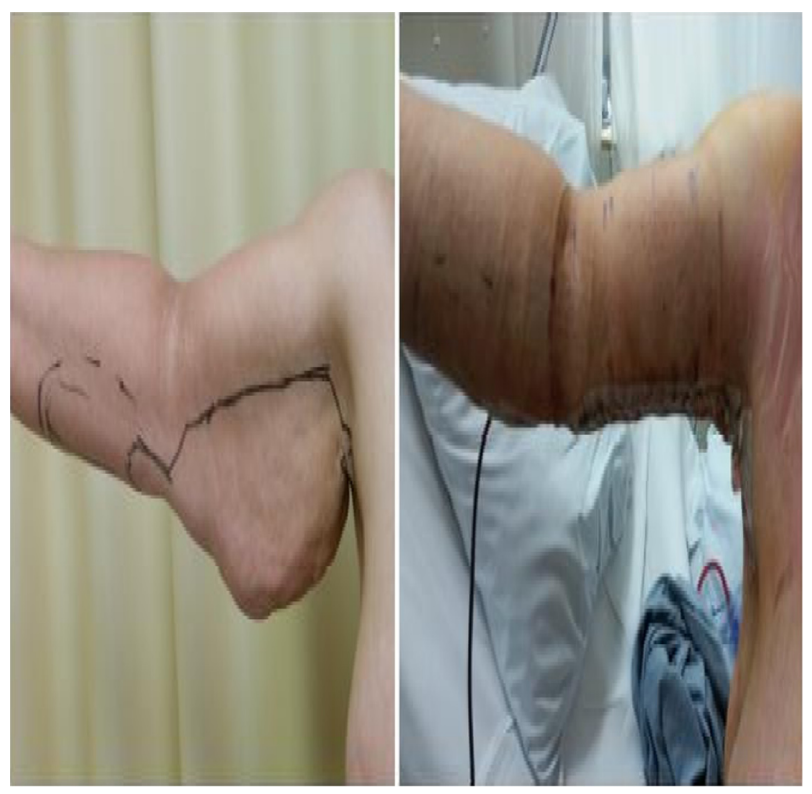

Figure I Brachioplasty. upper back, and the distance between them is determined by pinch test and scar location. Intraoperatively, the patient is first made to lie prone with arms at no greater than $90^{\circ}$ to avoid tension closure and the upper incision is made, and the back tissue is elevated inferiorly from the deep fascia. The amount of tissue removal is guided by the preoperative marks. Drains are placed laterally on each side and the incisions are sutured in layers. Then the patient is turned to a supine position in order to taper the back closure anteriorly (Figure 2). ${ }^{51}$

\section{Breast reshaping}

Breast deformities in postbariatric surgery patients can be different and very challenging. Usually, the main problems to be addressed are the ptosis, the loss of volume, and the redundant skin. Volume loss is proportional to weight loss, and the amount of residual gland determines the surgical choice. If the volume left is considered enough, a gland reshaping can be performed. If a volume increase is considered advisable, then a mammary implant is necessary. ${ }^{52}$ Round block techniques, with or without implants, are indicated in case of minor ptosis with a periareolar incision approach, ${ }^{53}$ including a complete undermining of the glandular upper pole in order to lift the breast, while the lower pole is left

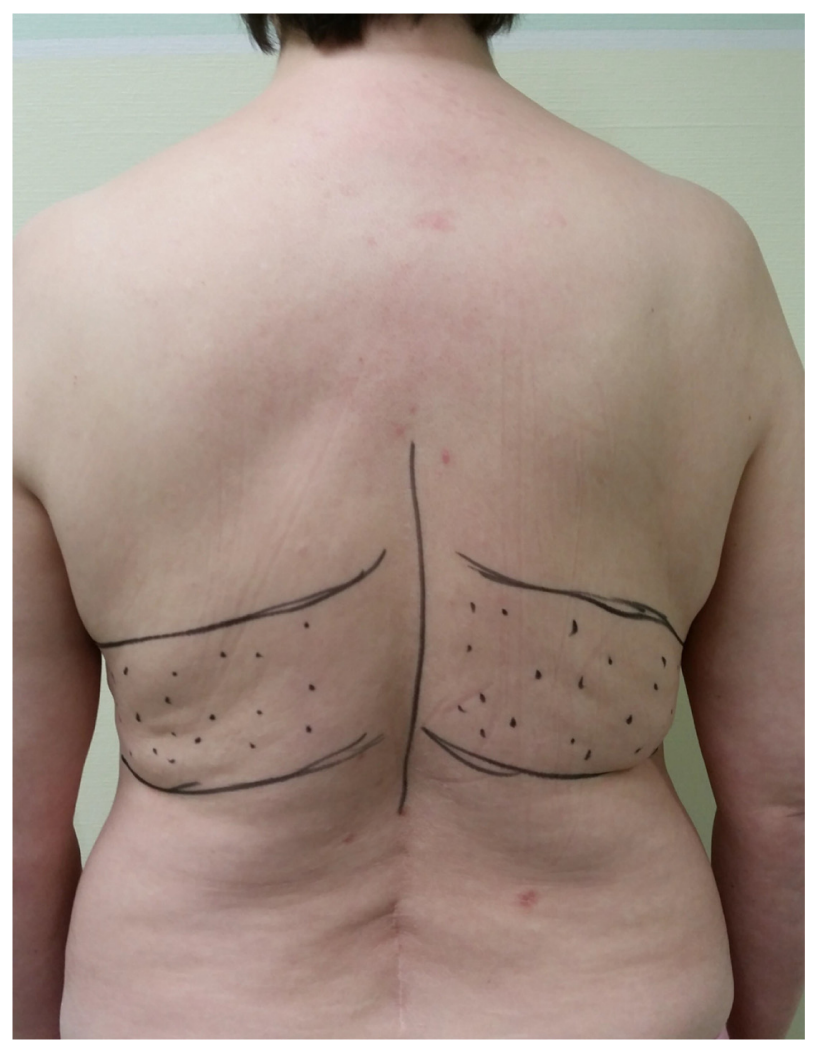

Figure 2 Upper back lift. 
undetached in order to guarantee a good blood perfusion. In case of pronounced ptosis (over $6 \mathrm{~cm}$ ), the L-technique is advisable, using a superior pedicle to support the nipple areola complex and breast suspension reducing and emphasizing the volume. Autoprosthesis can be used for glandular shaping, de-epithelializing, and harvesting flaps from the inferior or lateral part of the trunk and inserted in a pocket between the breast and the pectoralis major muscle fascia. If autoprosthesis cannot be performed and an implant is unavoidable, we prefer to harvest all the mammary glandular tissue on a superior pedicle. ${ }^{53}$ In many cases, the team option is a simple breast reduction (posteroinferior or superomedial pedicle, Figure 3).

\section{Abdominoplasty}

Indications for surgery include significant truncal skin redundancy and circumferential lipodystrophy, but abdominoplasty does not treat lipodystrophy in the peritoneal cavity. We prefer to first perform a lower back lift if a lower body lift/ belt lipectomy is planned.

The patient is marked, in a standing position, with a mark on the pubis $7 \mathrm{~cm}$ above the pubic cleft. Incision is extended from hip to hip along the upper lateral thigh to the waist. ${ }^{54} \mathrm{An}$ upper mark is estimated crossing the umbilicus. An additional liposuction may be performed at the same time. The surgery is performed with the patient in a supine position. Incisions are first made in the suprapubic area according to the preoperative markings, then around the umbilicus. Dissection is carried out through the subcutaneous fat to the rectus fascia, up to the xiphoid, taking care to spare soft tissue pads over the femoral triangles. ${ }^{51}$

If diastasis of rectus muscle is observed, a midline plication of the abdominal wall is performed. If hernias have been detected, they should be repaired at the same time as body-contouring procedures for the lower trunk. Particular attention should be taken if scars of previous abdominal
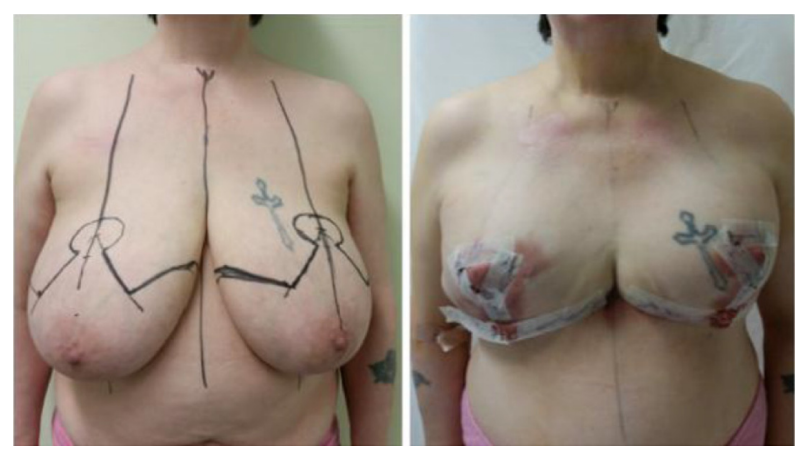

Figure 3 Breast reshaping. procedures are present, because they require special adjustments in planning and performing the procedure. Then, the new umbilical position is marked and the excess skin is removed in order to obtain an approximation, without significant skin tension. Skin closure is performed in layers with drains (Figure 4).

\section{Panniculectomy}

Some obese or postbariatric surgery patients may present with a panniculus morbidus. This excess pannus can limit exercise capabilities, can restrict hygiene, and may progress to a pathologic entity such as intertrigo, cellulitis, skin ulceration, and ischemic panniculitis. ${ }^{55}$ In extreme cases, a panniculus can have recurrent infections, ulcerate, and even necrose, requiring an emergency procedure.

Therefore, panniculectomy can be an adjuvant to bariatric surgery, and it can be beneficial for many patients undergoing weight reduction surgery, either done at the same time as bariatric surgery or later after significant weight reduction. ${ }^{56}$

With the patient preferably standing upright, the pannus is marked at the superior border to define the proposed extent of the elliptical resection. Using preoperative markings as a guide, the skin incision is started along the superior marks. The incision is then extended down through the subcutaneous fat layer and the dissection continues down to a plane superficial to the anterior abdominal fascia. ${ }^{57}$ Contrary to abdominoplasty, the upper abdominal flap is not undermined and the umbilicus cannot be preserved. Wound closure is performed in layers with drains (Figure 5).

\section{Lower back lift}

Lower back lift is usually performed when patients present with back skin laxity. Very often they have "saddlebag" collections of fat, so an additional liposuction will improve the contour and enhance the thigh lift. ${ }^{58}$ It is generally performed together with abdominoplasty for a circumferential belt
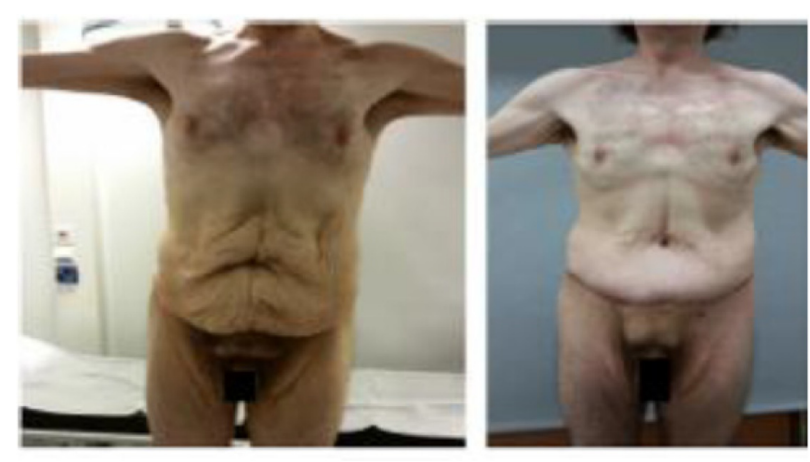

Figure 4 Abdominoplasty. 

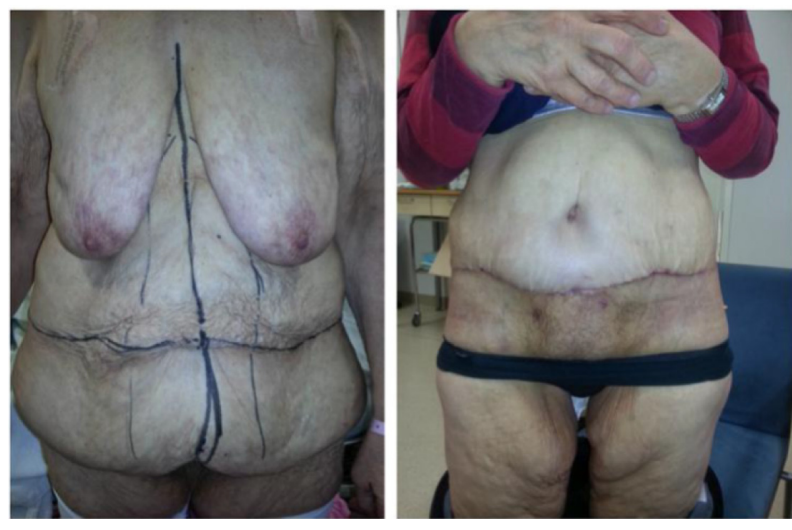

Figure 5 Panniculectomy.

lipectomy or lower body lift. Performing a gluteal reconstruction is crucial in order to avoid a flat buttock without waist definition. ${ }^{59}$ The patient is marked in the standing position. Superior and inferior marks are drawn across the lower back, and the distance between them is determined by pinch test and ultimate scar location. The marks are tapered anteriorly into the abdominoplasty markings for a circumferential belt lipectomy or into thigh-lift marks. If gluteal augmentation is planned, the proposed gluteal flaps are drawn between these marks and need to be low enough to allow rotation low into the buttock region. ${ }^{60}$

The procedure is first performed with the patient in a prone position, incisions are carried out till the deep fascia according to preoperative marks and excess tissue is elevated. Tailor tacking is always advisable to determine the tissue to be removed. If autogluteal augmentation is planned, the gluteal flaps are de-epithelialized and pockets are designed over the gluteal muscles where the flaps will be rotated. ${ }^{61}$ The patient is then turned into the supine position for the abdominoplasty. Thigh lift may also be performed at the same time, constituting a total lower body-lift procedure (Figure 6). ${ }^{52}$
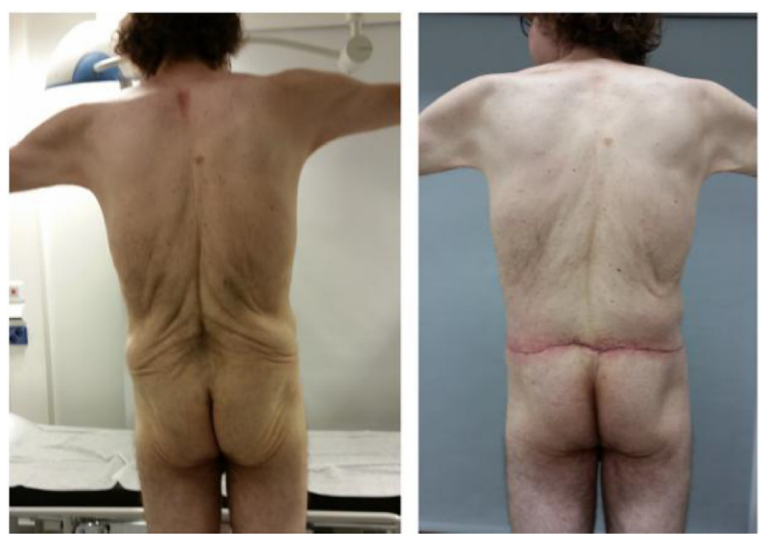

Figure 6 Lower back lift.

\section{Thigh lift}

Patients with laxity of the upper half of the thigh and good skin quality are good candidates for proximal thigh-lifting procedures, in whom scars could be hidden in the groin creases. However, if the excess skin of the thigh extends from the pubis, an extended thigh lift is indicated. ${ }^{62}$

Patients are marked in a standing position. The groin creases are marked symmetrically along the mons pubis edge, and the outer portion of the crescent excision is guided by pinch test to delineate the skin to be removed. The incisions may continue posteriorly into the infragluteal crease and superiorly into the abdomen to increase the skin removal. In case of the extended procedure, vertical incisions are also marked along the inner thigh, guided by pinch testing. ${ }^{62}$

The patient is in a supine position with the legs stabilized on the spreader bars during the procedure. The skin over the fascia overlying the thigh muscles is removed according to the preoperative marks, and soft tissue padding is conserved on the ischial bone. The inferior thigh skin flaps are approximated from Scarpa's fascia layer (superficial fascial system) to the ischial periosteum using a permanent suture, with an adequate periosteal bite ensuring fixation, in order to reduce complications related to the traction on the perineum and for a better long-term scar (Figure 7). ${ }^{62}$

\section{Postoperative complications}

Postbariatric surgery patients have a 60\%-87\% increased risk of complications compared with nonbariatric patients for body-contouring procedures after MWL. ${ }^{63}$ The most common complications seen after surgery include woundhealing problems, seromas and lymphoceles, infections, venous thromboembolism (1\%-9.3\%), ${ }^{12,39,41}$ hypothermia $\left(<35^{\circ} \mathrm{C}\right){ }^{38}$ lymphedema, hematomas, and nerve injury. Wound-healing problems are the most frequent after
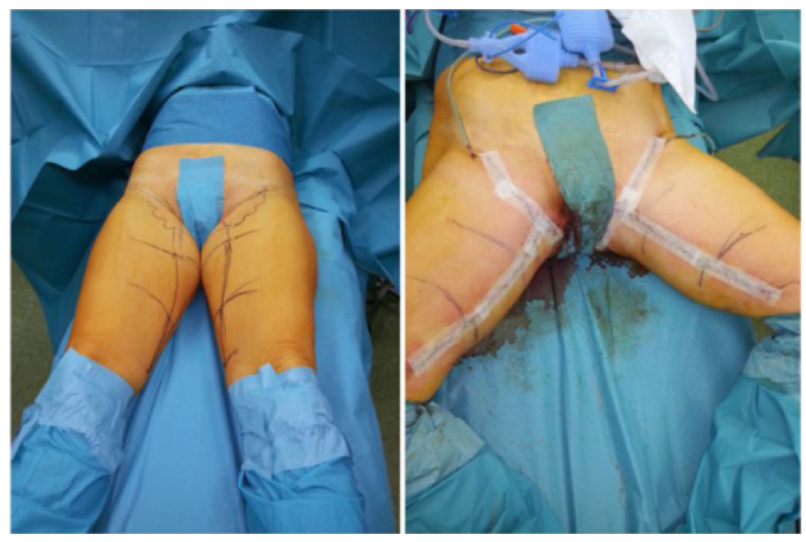

Figure 7 Thigh lift. 
body-contouring procedures, and they more often occur in patients with obesity, diabetes, endocrine disorders, EhlersDanlos syndrome, and autoimmune disease, advanced age, peripheral vascular, and coronary artery disease. .2,63,64 $^{2}$

Multiple comorbidities, presence of bleeding disorders, preoperative albumin level, and malnutrition have recently been significantly associated with increased odds of minor wound complications, ${ }^{20,65}$ while inpatient procedures and functional status have been linked with an increased odds of major surgical morbidity. ${ }^{66}$

\section{Benefits of body-contouring surgery after massive weight loss}

Patients experience an improved quality of life, self-esteem, sexual life, and body image after body-contouring surgery, ${ }^{32,67-69}$ also in the long run..$^{25,33}$ Only one recent study ${ }^{33}$ showed that patients electing to have body contouring after bariatric surgery had decreased quality of life even after plastic surgery compared to those patients who did not. This finding was probably due to unrealistic expectations. Nevertheless, body-contouring surgery not only improves the aesthetic outcomes but also corrects the functional impairment due to redundant $\operatorname{skin}^{25,34}$. Furthermore, it has also been demonstrated that patients with body contouring present with better long-term weight control after LRYGB. ${ }^{70}$ However, no correlation has been found between the amount of weight loss and improvement of quality of life. Therefore, for all these reasons, body-contouring surgery should be considered as a reconstructive operation in the treatment of morbid obesity in selected patients after MWL.

\section{Conclusion}

Postbariatric plastic surgery aims to treat both the functional and aesthetic problems caused by the surplus skin, increasing the patient's quality of life and self-esteem. These patients generally have very high expectations for both aesthetic outcomes and improved quality of life. ${ }^{24}$

There are discrepancies between patients who receive and who do not receive body-contouring surgery after MWL, which might be attributed to their social status. ${ }^{71}$ These procedures are not covered by third party payers in the USA but are usually restricted to abdominal problems, and only panniculectomies are covered. In addition, most of the patients cannot afford the cost of the surgery. ${ }^{72}$ Public insurance may offer and cover body-contouring procedures, but decisions have to be supported by appropriate indications. ${ }^{73}$

We believe that total weight loss and $\triangle \mathrm{BMI}$ are more important criteria for assessing this kind of patient rather than merely BMI. ${ }^{24,27}$ Particularly, it has been showed that a weight loss over $20 \mathrm{~kg}$ and a $\Delta \mathrm{BMI}>10 \mathrm{~kg} / \mathrm{m}^{2}$ might be considered for selecting patients for body-contouring surgery in a public health care insurance system. ${ }^{24,27}$

There is a lack of knowledge of the medical necessity criteria for these procedures in light of funding in insurance and public health systems. The average estimated cost of postbariatric surgery body contouring is relatively high, due to the multiple procedures, and it increases in case of complications. Therefore, it is very important to address coverage guidelines with an effort to unify them.

Health care professionals must address the current imbalance between requests for and the performance of bodycontouring surgery in adults and also in adolescents.

\section{Acknowledgment}

This paper is based on my doctoral thesis presented through the University of Turku in December 2014. Patient consent has been obtained for using patient photo.

\section{Disclosure}

No commercial associations or disclosures may pose, or create any conflict of interest with information presented in this paper.

\section{References}

1. NIH Consensus Development Conference Panel: gastrointestinal surgery for severe obesity. Ann Intern Med. 1991;115:956-961.

2. Gilbert EW, Wolfe BM. Bariatric surgery for the management of obesity: state of the field. Plast Reconstr Surg. 2012;130:948-954.

3. LiMen view on obesity [webpage on the Internet]. Available from: http://www.limery.fi/index.php?mid=2\&pid=8. Accessed May 24, 2015. Finnish.

4. WHO view on obesity [webpage on the Internet]. Available from: http:// www.euro.who.int/en/health-topics/noncommunicable-diseases/obesity. Accessed May 24, 2015.

5. Ogden CL, Carroll MD, Kit BK, Flegal KM. Prevalence of childhood and adult obesity in the United States, 2011-2012. JAMA. 2014;311(8): 806-814.

6. Pierpont YN, Dinh TP, Salas RE, et al. Obesity and surgical wound healing: a current review. ISRN Obes. 2014:638936.

7. Buchwald H, Avidor Y, Braunwald E, et al. Bariatric surgery. A systematic review and meta-analysis. JAMA. 2004;292:1724-1737.

8. Buchwald H, Estok R, Fahrbach K, et al. Weight and type 2 diabetes after bariatric surgery: systematic review and meta-analysis. Am J Med. 2009;122:248-256.e5.

9. Colquitt JL, Pickett K, Loveman E, Frampton GK. Surgery for weight loss in adults. Cochrane Database Syst Rev. 2014;8:CD003641.

10. Staalesen T, Fagevik Olsén M, Elander A. Experience of excess skin and desire for body contouring surgery in post-bariatric patients. Obes Surg. 2013;23(10):1632-1644.

11. Constantine RS, Davis KE, Kenkel JM. The effect of massive weight loss status, amount of weight loss, and method of weight loss on body contouring outcomes. Aesthet Surg J. 2014;34(4):578-583.

12. Michaels J 5th, Coon D, Rubin JP. Complications in postbariatric body contouring: postoperative management and treatment. Plast Reconstr Surg. 2011;127:1693-1700. 
13. Bossert RP, Rubin JP. Evaluation of the weight loss patient presenting for plastic surgery consultation. Plast Reconstr Surg. 2012;130(6): 1361-1379.

14. Bruschi S, Datta G, Bocchiotti MA, Boriani F, Obbialero FD, Fraccalvieri M. Limb contouring after massive weight loss: functional rather than aesthetic improvement. Obes Surg. 2009;19:407-411.

15. Gusenoff JA, Rubin JP. Plastic surgery after weight loss: current concepts in massive weight loss surgery. Aesthet Surg J. 2008;28(4): 452-455.

16. Wong WW, Gabriel A, Maxwell GP, Gupta SC. Bleeding risks of herbal, homeopathic, and dietary supplements: a hidden nightmare for plastic surgeons? Aesthet Surg J. 2012;32(3):332-346.

17. Gravante G, Araco A, Sorge R, Araco F, Delogu D, Cerbelli V. Wound infections in post-bariatric patients undergoing body contouring abdominoplasty: the role of smoking. Obes Surg. 2007;17 1325-1331.

18. Sørensen LT. Wound healing and infection in surgery: the pathophysiological impact of smoking, smoking cessation, and nicotine replacement therapy: a systematic review. Ann Surg. 2012;255(6):1069-1079.

19. Bloomberg RD, Fleishman A, Nalle JE, Herron DM, Kini S. Nutritional deficiencies following bariatric surgery: what have we learned? Obes Surg. 2005;15:145-154.

20. Naghshineh N, O’Brien Coon D, McTigue K, et al. Nutritional assessment of bariatric surgery patients presenting for plastic surgery: a prospective analysis. Plast Reconstr Surg. 2010;126:602-610.

21. Aldaqal SM, Samargandi OA, El-deek BS, et al. Prevalence and desire for body contouring surgery in postbariatric patients in Saudi Arabia. NAm J Med Sci. 2012;4(2):94-98.

22. Al-Hadithy N, Mennie J, Magos T, Stewart K. Desire for post bariatric body contouring in South East Scotland. J Plast Reconstr Aesthet Surg. 2013;66:87-94.

23. Kitzinger HB, Abayev S, Pittermann A, et al. After massive weight loss: patients' expectations of body contouring surgery. Obes Surg. 2012;22:544-548.

24. Giordano S, Victorzon M, Stormi T, Suominen E. Desire for body contouring surgery after bariatric surgery: do body mass index and weight loss matter? Aesthet Surg J. 2014;34(1):96-105.

25. van der Beek ES, van der Molen AM, van Ramshorst B. Complications after body contouring surgery in post-bariatric patients: the importance of a stable weight close to normal. Obes Facts. 2011;4:61-66.

26. Rubin JP, Jewell ML, Richter DF, Uebel CO. Body Contouring and Liposuction. Edinburgh, Scotland: Elsevier; 2012:386.

27. Giordano S, Victorzon M, Koskivuo I, Suominen E. Physical discomfort due to redundant skin in post-bariatric surgery patients. J Plast Reconstr Aesthet Surg. 2013;66(7):950-955.

28. Soldin M, Mughal M, Al-Hadithy N; Department of Health; British association of Plastic, Reconstructive and Aesthetic Surgeons; Royal College of Surgeons England. National commissioning guidelines: body contouring surgery after massive weight loss. J Plast Reconstr Aesthet Surg. 2014;67(8):1076-1081.

29. Setälä L, Kaarela O, Jyränki J. Plastic surgery needed after surgical treatment of obesity. Duodecim. 2012;128(24):2523-2528.

30. Post-bariatric surgery panel: the situation in Nordic countries. In: 34 th Congress of the Scandinavian association of plastic surgeons; June 13-16, 2012; Helsinki, Finland.

31. Song AY, Jean RD, Hurwitz DJ, Fernstrom MH, Scott JA, Rubin JP. A classification of contour deformities after bariatric weight loss: the Pittsburgh rating scale. Plast Reconstr Surg. 2005;116:1535-1544.

32. Klassen AF, Cano SJ, Scott A, Johnson J, Pusic AL. Satisfaction and quality-of-life issues in body contouring surgery patients: a qualitative study. Obes Surg. 2012;22:1527e34.

33. Modarressi A, Balagué N, Huber O, Chilcott M, Pittet-Cuénod B. Plastic surgery after gastric bypass improves long-term quality of life. Obes Surg. 2013;23:24-30.

34. Papadopulos NA, Staffler V, Mirceva V, et al. Does abdominoplasty have a positive influence on quality of life, selfesteem, and emotional stability? Plast Reconstr Surg. 2012;129:957ee62e.
35. Singh D, Zahiri HR, Janes LE, et al. Mental and physical impact of body contouring procedures on post-bariatric surgery patients. Eplasty. 2012;12:e47.

36. Song AY, Rubin JP, Thomas V, Dudas JR, Marra KG, Fernstrom MH Body image and quality of life in post massive weight loss body contouring patients. Obesity (Silver Spring). 2006;14:1626-1636.

37. Sarwer DB, Thompson JK, Mitchell JE, Rubin JP. Psychological considerations of the bariatric surgery patient undergoing body contouring surgery. Plast Reconstr Surg. 2008;121(6):423e-434e.

38. Coon D, Michaels J 5th, Gusenoff JA, Purnell C, Friedman T, Rubin JP. Multiple procedures and staging in the massive weight loss population. Plast Reconstr Surg. 2010;125(2):691-698.

39. Reish RG, Damjanovic B, Colwell AS. Deep venous thrombosis prophylaxis in body contouring: 105 consecutive patients. Ann Plast Surg. 2012;69(4):412-414.

40. Montano-Pedroso JC, Garcia EB, Omonte IR, Rocha MG, Ferreira LM. Hematological variables and iron status in abdominoplasty after bariatric surgery. Obes Surg. 2013;23(1):7-16.

41. Kim JY, Khavanin N, Rambachan A, et al. Surgical duration and risk of venous thromboembolism. JAMA Surg. 2015;150(2):110-117.

42. Kosins AM, Scholz T, Cetinkaya M, Evans GR. Evidence-based value of subcutaneous surgical wound drainage: the largest systematic review and meta-analysis. Plast Reconstr Surg. 2013;132(2): 443-450.

43. Pannucci CJ, Dreszer G, Wachtman CF, et al. Postoperative enoxaparin prevents symptomatic venous thromboembolism in high-risk plastic surgery patients. Plast Reconstr Surg. 2011;128(5):1093-1103

44. Toia F, D’Arpa S, Massenti MF, Amodio E, Pirrello R, Moschella F. Perioperative antibiotic prophylaxis in plastic surgery: a prospective study of 1,100 adult patients. J Plast Reconstr Aesthet Surg. 2012;65(5): 601-609.

45. Constantine FC, Matarasso A. Putting it all together: recommendations for improving pain management in body contouring. Plast Reconstr Surg. 2014;134(4 Suppl 2):113S-119S.

46. Giordano S, Veräjänkorva E, Koskivuo I, Suominen E. Effectiveness of local anaesthetic pain catheters for abdominal donor site analgesia in patients undergoing free lower abdominal flap breast reconstruction: a meta-analysis of comparative studies. J Plast Surg Hand Surg. 2013; 47(6):428-433.

47. Hurwitz DJ, Holland SE. The L-brachioplasty: an innovative approach to correct excess tissue of the upper arm, axilla, and lateral chest. Plast Reconstr Surg. 2006;117:403-411.

48. de Runz A, Colson T, Minetti C, et al; Liposuction-assisted medial brachioplasty after massive weight loss: an efficient procedure with a high functional benefit. Plast Reconstr Surg. 2015;135(1):74e-84e.

49. Chowdhry S, Elston JB, Lefkowitz T, Wilhelmi BJ. Avoiding the medial brachial cutaneous nerve in brachioplasty: an anatomical study. Eplasty. 2010;10:e16.

50. Shermak MA. Management of back rolls. Aesthet Surg J. 2008;28: 348-356.

51. Shermak MA, editor. Body Contouring. New York, NY: McGraw-Hill; 2011.

52. Migliori FC, Gabrielli A, Rizzo R, Serra Cervetti GG. Breast contouring in postbariatric patients: a technique selection algorithm. Obes Surg. 2010;20(5):651-656.

53. Hammond DC, Khuthila DK, Kim J. The interlocking gore-tex suture for control of areolar diameter and shape. Plast Reconstr Surg. 2007;119(3):804-809.

54. Eisenhardt SU, Goerke SM, Bannasch H, Stark GB, Torio-Padron N Technical facilitation of the fleur-de-lis abdominoplasty for symmetrical resection patterns in massive weight loss patients. Plast Reconstr Surg. 2012;129(3):590e-593e.

55. Friedrich JB, Petrov RV, Askay SA, et al. Resection of panniculus morbidus: a salvage procedure with a steep learning curve. Plast Reconstr Surg. 2008;121(1):108-114.

56. Acarturk TO, Wachtman G, Heil B, Landecker A, Courcoulas AP, Manders EK. Panniculectomy as an adjuvant to bariatric surgery. Ann Plast Surg. 2004;53(4):360-366. 
57. Zannis J, Wood BC, Griffin LP, Knipper E, Marks MW, David LR. Outcome study of the surgical management of panniculitis. Ann Plast Surg. 2012;68(2):194-197.

58. Aly AS, Cram AE, Chao M, Pang J, McKeon M. Belt lipectomy for circumferential truncal excess: the University of Iowa experience. Plast Reconstr Surg. 2003;111:398-413.

59. Centeno RF, Mendieta CG, Young VL. Gluteal contouring in the massive weight loss patient. Clin Plast Surg. 2008;35:73-91.

60. Pascal JF, Le Louarn C. Remodeling bodylift with high lateral tension. Aesthetic Plast Surg. 2002;26:223-230.

61. Shermak MA, Mallalieu JE, Chang D. Does thighplasty for upper thigh laxity after massive weight loss require a vertical incision? Aesthet Surg J. 2009;29:513-522.

62. Kenkel JM, Eaves FF III. Medial thigh lift. Plast Reconstr Surg. 2008; 122:621-622.

63. Hasanbegovic E, Sørensen JA. Complications following body contouring surgery after massive weight loss: a meta-analysis. J Plast Reconstr Aesthet Surg. 2014;67(3):295-301.

64. Albino FP, Koltz PF, Gusenoff JA. A comparative analysis and systematic review of the wound-healing milieu: implications for body contouring after massive weight loss. Plast Reconstr Surg. 2009;124(5): $1675-1682$.

65. Rieger UM, Erba P, Kalbermatten DF, Schaefer DJ, Pierer G, Haug M. An individualized approach to abdominoplasty in the presence of bilateral subcostal scars after open gastric bypass. Obes Surg. 2008;18: 863-869.
66. Fischer JP, Wes AM, Serletti JM, Kovach SJ. Complications in body contouring procedures: an analysis of 1797 patients from the 2005 to 2010 American College of Surgeons national surgical quality improvement program databases. Plast Reconstr Surg. 2013;132(6):1411-1420.

67. Coriddi MR, Koltz PF, Chen R, Gusenoff JA. Changes in quality of life and functional status following abdominal contouring in the massive weight loss population. Plast Reconstr Surg. 2011;128:520-526.

68. Lazar CC, Clerc I, Deneuve S, Auquit-Auckbur I, Milliez PY. Abdominoplasty after major weight loss: improvement of quality of life and psychological status. Obes Surg. 2009;19:1170e5.

69. Azin A, Zhou C, Jackson T, Cassin S, Sockalingam S, Hawa R. Body contouring surgery after bariatric surgery: a study of cost as a barrier and impact on psychological well-being. Plast Reconstr Surg. 2014;133(6): 776e-782e.

70. Balagué N, Combescure C, Huber O, Pittet-Cuénod B, Modarressi A. Plastic surgery improves long-term weight control after bariatric surgery. Plast Reconstr Surg. 2013;132(4):826-833.

71. Gusenoff JA, Pennino RP, Messing S, et al. Post-bariatric surgery reconstruction: patient myths, perceptions, cost, and attainability strategies. Plast Reconstr Surg. 2008;122(1):1e-9e.

72. Gurunluoglu R. Insurance coverage criteria for panniculectomy and redundant skin surgery after bariatric surgery: why and when to discuss. Obes Surg. 2009;19(4):517-520.

73. Sati S, Pandya S. Should a panniculectomy/abdominoplasty after massive weight loss be covered by insurance? Ann Plast Surg. 2008;60(5): $502-504$.
Open Access Surgery

\section{Publish your work in this journal}

Open Access Surgery is an international, peer-reviewed, open access journal that focuses on all aspects of surgical procedures and interventions. Patient care around the peri-operative period and patient outcomes post surgery are key topics. All grades of surgery from minor cosmetic interventions to major surgical procedures are covered. Novel techniques

Submit your manuscript here: http://www.dovepress.com/open-access-surgery-journal

\section{Dovepress}

and the utilization of new instruments and materials, including implants and prostheses that optimize outcomes constitute major areas of interest. The manuscript management system is completely online and includes a very quick and fair peer-review system. Visit http://www.dovepress.com/ testimonials.php to read real quotes from published authors. 